\title{
Influence of FMD vaccination stress on milk production in crossbred dairy cattle of Kerala
}

\author{
Pramod S, R ThirupathyVenkatachalapathy, Lasna Sahib and Bibin Becha B
}

Received: 18 June 2020 / Accepted: 24 November 2020 / Published online: 28 February 2021

(C) Indian Dairy Association (India) 2021

\begin{abstract}
Foot and mouth disease (FMD) is a contagious viral disease affecting cloven-footed animals which is endemic in India. The primary disease control strategy in India is mass vaccination using oil adjuvant killed FMD vaccine containing $\mathrm{O}$, A and Asia 1 serotypes. Variations in milk yield following vaccination with oil adjuvant killed FMD vaccine was studied in 80 crossbred cattle, maintained at Livestock Research Station, Thiruvazhamkunnu for eight days. The study was conducted in August 2019. Rectal temperature, temperature-humidity index (THI) and milk quality were also monitored. Immunization resulted in transient febrile reaction $\left(103.03 \pm 0.24{ }^{\circ} \mathrm{F}\right)$ and a significant reduction in milk yield $(\mathrm{p}<0.01)$. The average milk production (mean $\pm \mathrm{SE}$ ) before vaccination was $7.68 \pm 0.28 \mathrm{~kg}$, which dropped to $7.07 \pm 0.28 \mathrm{~kg}$, on the day after vaccination. The highest losses were observed on the first day after vaccination, with a mean of $0.58 \pm 0.09 \mathrm{~kg}$. Milk quality remained unaffected. Total milk yield of the herd rebounded to pre-vaccination levels by the sixth day after vaccination. The average cumulative production loss calculated over the period was $1.93 \mathrm{Kg}$ per animal. Notable changes in feed or water consumption were not observed. The study observed that production loss due to vaccination is negligible in comparison to potential losses due to FMD in a herd.
\end{abstract}

Keywords: FMD vaccination, Milk production, Production loss, Vaccination stress

Kerala Veterinary and Animal Sciences University, Livestock Research Station, Thiruvazhamkunnu, Palakkad, Kerala, India

Thirupathy V R ( $₫)$

Kerala Veterinary and Animal Sciences University, Livestock Research Station, Thiruvazhamkunnu, Palakkad, Kerala, India

Email: thirupathy@kvasu.ac.in

\section{Introduction}

Vaccination introduces killed or attenuated pathogens into the body of an animal, forcing the host to mount an immune response, as if it were a real infection. Injectible vaccines contain preservatives and materials like mineral oils which keep the antigens in suspension to prolong the immune reaction and to raise antibody titre to a protective level. Stress due to vaccination arises from the act of handling, injection and inflammatory reactions (Jo et al. 2014).

Foot and mouth disease (FMD) is a contagious viral disease affecting cloven-footed animals which is endemic in India. Office International des E'pizooties (OIE) recognized FMD as the most important constraint to international trade of animals and animal products. Losses of production, retarded growth, abortion, subfertility, etc. are noticed in recovered animals which erode the profitability of farming and drain the resources of the farmers (Pawar et al. 2010). Direct and indirect losses after the FMD outbreak are well studied, as indicated by publications by Laria et al. (2017); Baluka, (2016) and Sharma et al.(2016), among others. Anti FMD vaccination drives often stir discussions about production loss in the post-vaccination period among livestock farmers and technical personnel working alongside them. However, publications addressing this problem after vaccination in cattle were rare, which inspired the present study. The work was conducted at Livestock Research Station, Thiruvazhamkunnu (LRST) under Kerala Veterinary and Animal Sciences University to ascertain whether vaccination against FMD caused a significant reduction in milk yield or quality in the immediate post-vaccination period.

\section{Materials and Methods}

Crossbred lactating animals $(n=80)$, maintained at Livestock Research Station, Thiruvazhamkunnu Tunder uniform management conditions were vaccinated using oil adjuvant FMD vaccine in August 2019. Milk production, milk quality parameters (viz. fat, solids not fat (SNF), protein, lactose content) and rectal temperatures were monitored after vaccination as detailed below. Milk production records $(n=640)$ starting from one day before vaccination (day -1), the day of vaccination (day 0) and until six 
days after vaccination (day 1 to day 6) were monitored. Animals were classified based on the number of days in milk as early stage (0-100 days), mid stage (101-200 days) and later stage( $>200$ days) as suggested by Vijayakumar et al. (2017). There were 25 animals in the early stage, 27 animals in mid stage and 28 cows in the late stage of lactation. Rectal temperatures from a subsample of 12 animals were recorded using a digital thermometer (Omron) at daily intervals until day 4, starting from day 0. Milk quality parameters were quantified using Ekomilk Ultra pro milk analyzer (Milkana KAM98-2A) ultrasonic milk tester from another subset of six animals using samples collected from forenoon and afternoon milking. Temperature humidity index (THI) was calculated with data available from an automatic weather station (Campbell Scientific, CR 800 series data logger) maintained on the campus. The formula developed by Clemson University, USA, THI $=\mathrm{T}_{\text {air }}$ " $(0.55 "[0.55 \mathrm{xRH} / 100]) \times\left(\mathrm{T}_{\text {air }}{ }^{-}\right.$ 58.8) where, $\mathrm{THI}=$ Temperature Humidity Index, $\mathrm{T}_{\text {air }}=$ air temperature in Fahrenheit, RH =percent relative humidity(Kohli et al. 2014; Habeeb et al.2018) was used for calculating THI. Production data were analyzed using records of day 0 (day of vaccination) and day 1 (24 hrs after vaccination) with a paired sample t-test. Multiple paired t-tests with respect to day 0 were done to follow the variables throughout the period of study. Production losses were estimated based on the assumption that vaccination stress alone was the reason for the deviation, considering production on day 0 , as the baseline production, whenever such differences appeared statistically significant.

\section{Results and Discussion}

Animals were maintained under uniform management conditions during the period of the study. Changes in feeding or drinking pattern were not observed. None of the animals were treated for systemic diseases or mastitis during the period of the study. Rectal temperature of animals, ambient temperature (average), ambient temperature (maximum), relative humidity (average) and temperature-humidity index observed/calculated during the first five days of study are presented in Table 1 .

Weather parameters monitored during the period of the study indicated that the animals were more or less under uniform thermal stress. Cows were under mild thermal stress when THI remained between 72 and 79 . The stress increased to a moderate level when THI was between 79 and 89(Kohli et al. 2014; Habeeb et al.

Table 1 Mean rectal temperature, weather parameters and THI

\begin{tabular}{|c|c|c|c|c|c|c|c|}
\hline \multirow[t]{2}{*}{$\overline{\text { Days }}$} & \multicolumn{3}{|c|}{ Temperature } & \multicolumn{2}{|c|}{ Relative humidity } & \multicolumn{2}{|c|}{ THI } \\
\hline & $\begin{array}{l}\text { Rectal }\left({ }^{\circ} \mathrm{F}\right) \\
\operatorname{Mean} \pm \mathrm{SE}\end{array}$ & $\begin{array}{l}\text { Ambient } \\
\left(\text { Max, }{ }^{\circ} \mathrm{C}\right)\end{array}$ & $\begin{array}{l}\text { Ambient } \\
\left(\text { Avg, }{ }^{\circ} \mathrm{C}\right)\end{array}$ & $\begin{array}{l}\text { RH } \\
(\text { Avg) }\end{array}$ & $\begin{array}{l}\mathrm{RH} \\
\text { (Max) }\end{array}$ & Avg & Max \\
\hline$\overline{0}$ & $102.28 \pm 0.30$ & 30.37 & 25.31 & 98.30 & 99.00 & 77.45 & 86.51 \\
\hline 1 & $103.03 \pm 0.24$ & 31.07 & 25.63 & 97.30 & 100.0 & 78.13 & 87.93 \\
\hline 2 & $101.95 \pm 0.09$ & 30.36 & 25.33 & 95.50 & 99.70 & 77.56 & 86.60 \\
\hline 3 & $101.75 \pm 0.16$ & 29.06 & 25.07 & 97.60 & 98.70 & 76.99 & 84.13 \\
\hline 4 & $100.93 \pm 0.22$ & 28.78 & 24.30 & 100.0 & 100.0 & 75.74 & 83.80 \\
\hline
\end{tabular}

Table 2 Mean ( \pm SE)milk composition (\%)

\begin{tabular}{|c|c|c|c|c|c|c|c|c|}
\hline$\overline{\text { Days }}$ & & Forenoon & $(n=6)$ & & & Afternoon & $(\mathrm{n}=6)$ & \\
\hline & Fat & SNF & Lactose & Protein & Fat & SNF & Lactose & Protein \\
\hline$\overline{0}$ & $2.99 \pm 0.29$ & $7.42 \pm 0.17$ & $3.89 \pm 0.10$ & $2.95 \pm 0.05$ & $5.38 \pm 0.45$ & $7.54 \pm 0.16$ & $3.97 \pm 0.09$ & $2.98 \pm 0.05$ \\
\hline 1 & $2.80 \pm 0.23$ & $7.56 \pm 0.11$ & $4.00 \pm 0.06$ & $2.98 \pm 0.04$ & $4.43 \pm 0.20$ & $7.39 \pm 0.11$ & $3.88 \pm 0.06$ & $2.94 \pm 0.04$ \\
\hline 2 & $3.10 \pm 0.20$ & $7.88 \pm 0.32$ & $4.17 \pm 0.18$ & $3.10 \pm 0.11$ & $4.63 \pm 0.22$ & $7.22 \pm 0.06$ & $3.78 \pm 0.03$ & $2.88 \pm 0.02$ \\
\hline 3 & $3.19 \pm 0.43$ & $8.01 \pm 0.25$ & $4.24 \pm 0.13$ & $3.15 \pm 0.08$ & $4.62 \pm 0.18$ & $7.49 \pm 0.20$ & $3.94 \pm 0.11$ & $2.97 \pm 0.07$ \\
\hline
\end{tabular}

Table 3 Mean total milk production during pre/post-vaccination period

\begin{tabular}{|c|c|c|c|c|c|c|}
\hline \multirow{2}{*}{$\begin{array}{l}\text { Pre/Post- } \\
\text { vaccination } \\
\text { period }\end{array}$} & \multicolumn{2}{|c|}{ Forenoon $(\mathrm{n}=80)$} & \multicolumn{2}{|c|}{$\begin{array}{l}\text { Milk Production (Mean } \pm \text { SE, } k g) \\
\text { Afternoon }(n=80)\end{array}$} & \multicolumn{2}{|c|}{ Total $(\mathrm{n}=80)$} \\
\hline & Total & Mean & Total & Mean & Total & Mean \\
\hline Day -1 & 393.0 & $4.91 \pm 0.18$ & 221.0 & $2.76 \pm 0.10$ & 614.0 & $7.68 \pm 0.28$ \\
\hline Day 0 & 393.5 & $4.92 \pm 0.17$ & 218.5 & $2.73 \pm 0.11$ & 612.0 & $7.65 \pm 0.28$ \\
\hline Day 1 & 358.0 & $4.48 \pm 0.18^{* *}$ & 207.5 & $2.59 \pm 0.12^{*}$ & 565.5 & $7.07 \pm 0.27^{* *}$ \\
\hline Day 2 & 377.0 & $4.71 \pm 0.18^{* *}$ & 204.0 & $2.55 \pm 0.11 * *$ & 581.0 & $7.26 \pm 0.28^{* *}$ \\
\hline Day 3 & 379.5 & $4.74 \pm 0.17$ & 212.0 & $2.65 \pm 0.10$ & 591.5 & $7.39 \pm 0.27^{*}$ \\
\hline Day 4 & 378.5 & $4.73 \pm 0.17 *$ & 210.0 & $2.63 \pm 0.09$ & 588.5 & $7.36 \pm 0.26^{* *}$ \\
\hline Day 5 & 366.0 & $4.58 \pm 0.18^{* *}$ & 213.5 & $2.67 \pm 0.10$ & 579.5 & $7.24 \pm 0.27 * *$ \\
\hline Day 6 & 383.5 & $4.79 \pm 0.18$ & 216.5 & $2.71 \pm 0.10$ & 600.0 & $7.50 \pm 0.28$ \\
\hline
\end{tabular}

${ }^{* *} \mathrm{P}<0.01,{ }^{*} \mathrm{P}<0.05$, Superscripts indicate a significant difference between rows from day 0 
2018). Animals remained under mild stress most of the time, which exacerbated to moderate stress when daily temperatures peaked. Therefore, it is reasonable to assume that production loss observed in the study on the first day after immunization was due to vaccination stress. Rectal temperatures of the sampled animals were elevated by about $1^{\circ} \mathrm{F}$ on the first day after vaccination. Though the increase in rectal temperature was not statistically significant, it was in the range of mild pyrexia, since the normal rectal temperature reported for a dairy cow was 100.4 to $102.8^{\circ} \mathrm{F}$ (Susan et al. 2016). The average rectal temperature returned to baseline on the second day after vaccination and dropped consistently over the following days. A similar finding was reported in buffaloes, except that temperatures were recorded on day 3 after vaccination against FMD and fever was not noted (Sivajothi et al. 2018). Pyrexia could be due to the use of oil adjuvant which was known to induce reactions, like granuloma, abscesses or fever (Aucouturier et al. 2001).

Milk quality parameters remained unaffected by vaccination stress. The mean \pm SE values (\%) of fat, SNF, lactose and protein observed in the present study are presented in Table 2. Observations from the present study coincide with the report by Rao et al. (2017) in this regard. Another interesting finding was that SNF in milk level remained below specifications $(8.3 \%)$ maintained by food safety and standards regulations (2019). Fat content was also lower than specifications (3.2\%) in the forenoon milk samples.

Milk production remained stable on the day of vaccination and the previous day. The average milk production (mean $\pm \mathrm{SE}$ ) of the animals on the day before vaccination was $7.68 \pm 0.28 \mathrm{~kg}$, which dropped to $7.07 \pm 0.28 \mathrm{~kg}$, after vaccination. Consequently, milk production of the herd decreased by about 7.6 percent from 612 $\mathrm{kg}$ to $565.5 \mathrm{~kg}$. The summary of post-vaccination milk production is presented in Table 3. A significant drop $(\mathrm{P}<0.01)$ in total milk production was noticed between day 0 and day 1 in animals across all stages of lactation. Both forenoon $(\mathrm{P}<0.01)$ and afternoon $(\mathrm{P}<0.05)$ milk productions differed significantly between day 0 and day 1 . The difference in total milk production of herd with respect to day 0 remained significant until day 5 after vaccination.

The mean milk production for different stages of lactation is presented in Table 4. Total milk yield, ie. sum of forenoon and afternoon production; was reduced significantly in animals across all the three stages of lactation on day 1 after vaccination. Further, it remained significantly reduced on day 2 after vaccination in early lactation and mid-lactation animals. In early and midlactation groups, no significant difference was observed in forenoon milk production after vaccination. However, forenoon milk yield dropped significantly among animals in late lactation.

Significant reduction in milk yield was observed in afternoon milk production on day $2(\mathrm{P}<0.01)$, day $4(\mathrm{P}<0.05)$ and day 5 $(\mathrm{P}<0.05)$ after vaccination inthe early lactation group. In mid

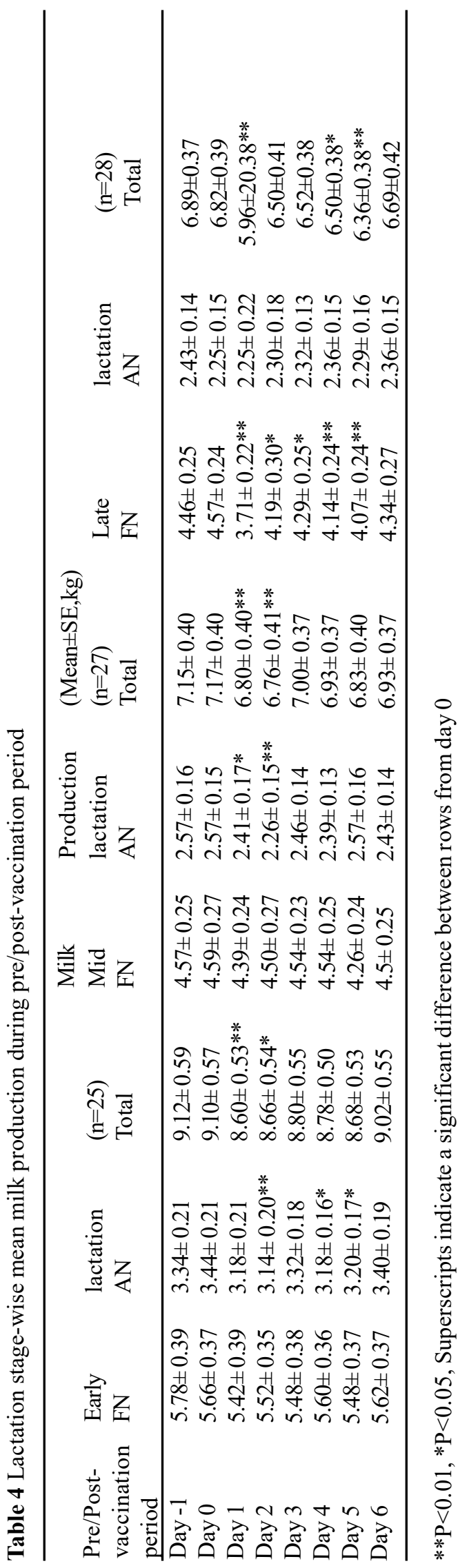



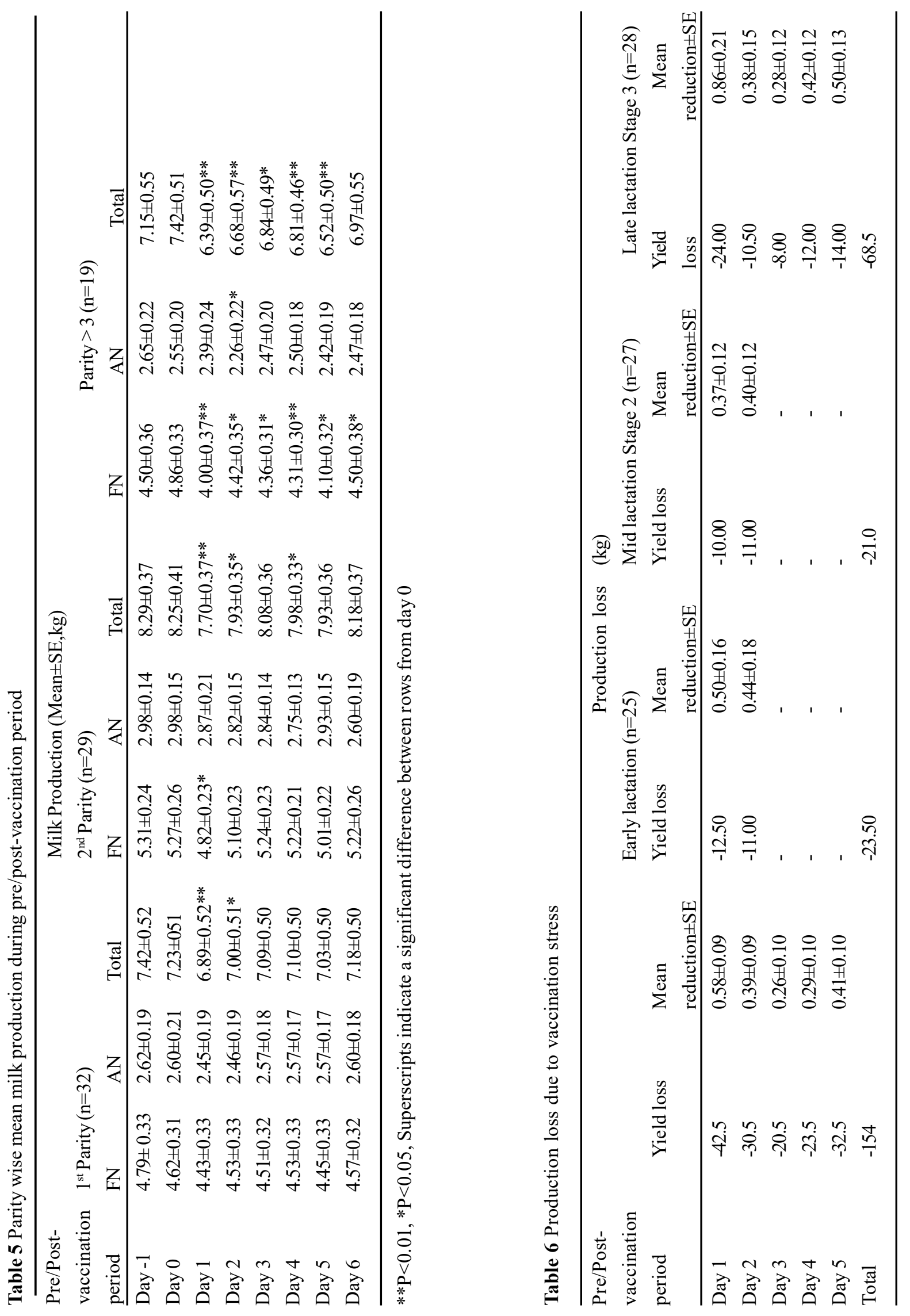
lactating animals, afternoon milk yield was significantly reduced on day 1 and day 2 after vaccination. However, no significant change was noticed in the afternoon milk yield of cattle in late lactation.

The parity wise mean milk production is presented in Table 5. A significant drop in milk production $(\mathrm{P}<0.01)$ was observed on day 1 after vaccination across all parity groups. Forenoon milk production was also reduced in second parity animals $(\mathrm{P}<0.05)$ and $>3$ parity group $(\mathrm{P}<0.01)$ on day 1 after vaccination. Average milk production in the forenoon remained significantly lower even on the $6^{\text {th }}$ day after vaccination among animals of third and higher parity. Total milk production remained significantly reduced until 5 days after vaccination.

Cumulative losses with respect to total yield stood at $154.0 \mathrm{Kg}$, from day 1 to day 5 after vaccination, during which such differences were statistically significant. Production loss observed in the study due to vaccination stress is presented in Table 6.

The highest drop in milk yield was observed (7.6\%) on the first day after vaccination, which averaged at $0.58 \mathrm{Kg}$ per animal. Total milk yield returned to the baseline on the $6^{\text {th }}$ day after vaccination. The average production loss calculated over the period was 1.93 $\mathrm{Kg}$ per animal .Among animals in late lactation, forenoon milk yield alone was affected, while afternoon yields remained stable. Nearly half of the animals in the third and higher parity group $(n=9)$ were also in the late stage of lactation. Animals in the third stage of lactation were severely affected by vaccination stress so that they accounted for $44.5 \%$ of the total loss, besides taking 5 days to regain yield. Working in temperate regions, Canadian researchers (temperate region) reported that Holstein Frisian animals in early lactation suffered the highest production loss (Scott et al. 2001) after immunization with 9 way killed vaccines. This result is in contrast with the findings of the present study. The differences could be attributed to environmental and genetic factors.

Milk production loss after FMD outbreak among 59 cattle at Chazhoor panchayath in Thrissur district of Kerala was estimated at $80.68 \%$ and was valued at Rs. 2.53 Lakhs. The loss per animal in this regard was roughly 4,300 Rupees or USD 63 (Mathew and Menon, 2008). The loss observed in the present study due to stress following FMD vaccination was about Rupees 100 (USD 1.5) per animal which is negligible in comparison with probable post-outbreak losses.

\section{Conclusions}

Vaccination against FMD using oil adjuvant vaccines resulted in febrile reaction and production loss. Total milk yield regained to pre-vaccination levels on the sixth day after vaccination. Among early lactation and mid-lactation animals, total production returned to pre-vaccination level as early as the third day after vaccination.
In the late lactation group, afternoon production remained stable even though forenoon yields returned to pre-vaccination state only after five days. The present study was conducted during the southwest monsoon when climate related stress remained at a mild to moderate level. The production loss could probably exceed $7.6 \%$ when other factors like heat stress in summer comes into play. This study throws some light on the need to formulate guidelines to reduce the stress associated with FMD vaccination and the season of vaccination. Loss in milk production due to vaccination stress is negligible when compared with potential loss due to the FMD outbreak.

\section{Acknowledgments}

The study was supported by the State plan project (2018-19) "Improvement of milk production in cattle and goats at LRST" funded by the Government of Kerala.

\section{References}

Aucouturier J, Dupuis L, Ganne V (2001) Adjuvants designed for veterinary and human vaccines. Vaccine 19: 2666-2672

Baluka SA (2016) Economic effects of foot and mouth disease outbreaks along the cattle marketing chain in Uganda. Vet World 9: 544-553

Habeeb AA, Gad AE, Atta, MA (2018) Temperature-humidity indices as indicators to heat stress of climatic conditions with relation to production and reproduction of farm animals. Int J Biotechnol. Recent Adv1: 35-50

Jo NC, Jung J, Kim JN, Lee J, Jeong SY, Kim W, Sung HG, Seo S (2014) Effect of vaccination against foot-and-mouth disease on growth performance of Korean native goat (Capra hircuscoreanae). J Anim Sci 92: 2578-2586

Kohli S, Atheya UK, Thapliyal A (2014) Assessment of optimum thermal humidity index for crossbred dairy cows in Dehradun district, Uttarakhand, India. Vet World 7: 916-921

Laria MA, Fani MM, Lyons NA, Azizi N (2017) Impact of FMD outbreak on milk production and heifers' growth on a dairy herd in southern Iran. Prev Vet Med 144: 117-122

Mathew L, Menon DG (2008) Economic impact of FMD in Chazhoor panchayath. Vet World 1: 5-6

Pawar SS, Tamilselvan RP, Saravanan S, Sanyal A, Mohapatra JK, Pattnaik B (2010) Foot and Mouth Disease (FMD): India and the world. Sci India 13: 36-42

Rao TKS, Kumar B, Sharma VK, Sriranga KR, Baishya A, Bhakat M, Mohanty TK (2017) Effect of vaccination on performance of dairy animals with special reference to bulls: a review. Theriogenol Insight 7: $185-197$

Scott HM, Atkins G, Willows B, McGregor R (2001) Effects of 2 commercially-available 9 -way killed vaccines on milk production and rectal temperature in Holstein-Friesian dairy cows. Can Vet $\mathrm{J}$ 42: 793-798

Sharma VB, Verma MR, Qureshi S, Bharti P (2016) Effects of diseases on milk production and body weight of cattle in Uttar Pradesh. IJAEB 9: $463-465$

Sivajothi S, Reddy YVP, Reddy S, Vani S, Chandel S (2018) Evaluation of herbal anti-stressor product (Restobal) during the vaccination stress in buffaloes. Int J Curr Microbiol App Sci 7: 723-727

Susan EA, Michael AM, Dana GA (2016) The Merck Veterinary Manual. $11^{\text {th }}$ Ed. Merck \& Co., New Jersey

Vijayakumar M, Park JH, Ki, KS, Lim DH, Kim SB, Park SM, Jeong HY, Park BY, Kim TI (2017) The effect of lactation number, stage, length, and milking frequency on milk yield in Korean Holstein dairy cows using automatic milking system. Asian Australas J Anim 30: 1093-1098 